\title{
SUBMITTED VERSION
}

Manasi Murthy Mittinty, Daniel W. McNeil, Lisa M. Jamieson

Limited evidence to measure the impact of chronic pain on health outcomes of indigenous people

Journal of Psychosomatic Research, 2018; 107:53-54

(C) 2018 Elsevier Inc. All rights reserved.

Published at: http://dx.doi.org/10.1016/i.jpsychores.2018.02.001

PERMISSIONS

https://www.elsevier.com/about/policies/sharing

Preprint

- Authors can share their preprint anywhere at any time.

- If accepted for publication, we encourage authors to link from the preprint to their formal publication via its Digital Object Identifier (DOI). Millions of researchers have access to the formal publications on ScienceDirect, and so links will help your users to find, access, cite, and use the best available version.

- Authors can update their preprints on arXiv or RePEc with their accepted manuscript .

Please note:

- Some society-owned titles and journals that operate double-blind peer review have different preprint policies. Please check the journals Guide for Authors for further information

- Preprints should not be added to or enhanced in any way in order to appear more like, or to substitute for, the final versions of articles.

17 March 2020 


\section{Limited evidence to measure the impact of chronic pain on health outcomes of Indigenous people.}

Manasi Murthy Mittinty ${ }^{\mathrm{a}, *}$, Daniel W McNeil ${ }^{\mathrm{b}}$, Lisa M Jamieson ${ }^{\mathrm{c}}$

${ }^{a}$ Indigenous Oral Health Unit, The University of Adelaide, Australia

${ }^{\mathrm{b}}$ Department of Psychology, West Virginia University, Morgantown, USA.

${ }^{c}$ Indigenous Oral Health Unit, The University of Adelaide, Australia

*Corresponding author at Research Fellow, Indigenous Oral Health Unit, The University of Adelaide, 57 North Terrace, Adelaide, Australia, 5006

Email address: manasi.mittinty@ adelaide.edu.au (M Mittinty). 
Pain defined as an "unpleasant sensory and emotional experience associated with actual or potential tissue damage, or described in terms of such damage" [1], is a major health care crisis of this century. It is also one of the leading causes for health service utilisation in Australia, costing $\$ 34$ billion per annum to the economy [2]. The number of lives affected by pain would be very high, if the emotional, physical, and financial challenges of those caring for people experiencing pain were added up.

Pain is often differentiated as either chronic or acute, both of which are important issues in the human experience and in healthcare. However, Australia is currently facing an exploding epidemic of chronic pain [3]. Primarily because chronic pain typically is not a straightforward physical problem but is accompanied with psychological, emotional and social distress, which challenges its management especially for cultural minority groups. Cultural and social environment, which is inclusive of beliefs, customs, languages, relationships with self, society and environment significantly influences how an individual experiences pain (which is defined in terms as a psychological experience-with emotional and behavioural components). Culture can also encourage adverse health beliefs [4], which are central to negative experiences with health care [5,6]. It is therefore imperative to understand the cultural epidemiology of pain to understand how culture and belief system influence the pain experience for Australia's most marginalised populations, Indigenous Australians. This will allow us to expand our understanding of psychological (thoughts, feelings, behaviours) and social (culture, networks) factors guiding the pain experienced by Indigenous Australians.

Despite access to pain management being declared as a fundamental human right [7] pain essentially remains unrecognised as a health concern for Indigenous populations. Although pain forms an indivisible component of the major health conditions linked with poor life expectancy in the Australian Indigenous population; cardiovascular disease, lung disease, diabetes, chronic kidney disease, musculoskeletal disease and cancer. The 2017 report from the Australian Bureau of Statistics [8], did not include pain as a health outcome or indicator for Indigenous Australians. Pain on its own or as an adjunct may cause severe physical disability and emotional and social suffering and depression, which may further culminate into unemployment, low self-worth, and social isolation. Lower socio-economic status and poor access to effective pain management further increases Indigenous communities' risk of living with chronic painful conditions [9], which further highlights the need to evaluate and treat pain in this vulnerable group. This gap in knowledge about pain experience of Indigenous 
populations is acknowledged by Australia's National Health and Medical Research Council [10].

Majority of the current literature on pain, report on findings from studies conducted largely on Caucasian populations. There are limited studies informing the concepts of pain, pain assessment and pain relief amongst Indigenous people, both in the Australian and international contexts [11]. Studies suggests that Indigenous people exhibit less observable pain behaviours $[12,13]$ and a reluctance to discuss the origin of their pain [11], plausibly because pain which diminishes strength is viewed as a weakness [14]. However, these scales used in these studies for measuring pain intensity, functioning (physical, emotional, cognitive) and impact in Indigenous people are set to standards based on data collected from non-Indigenous populations. It is plausibly, that these standards fail to fully capture the circumstances of Indigenous Australians, particularly their relationship to country and the importance of the holistic framework when considering their overall health and social/emotional wellbeing. The frame of reference that Indigenous Australians use to conceptualise pain may not be the same as that of the non-Indigenous populations [12] for example Indigenous patients may not be able to report experience of pain on a numerical rating scale.

In addition, stereotypes that Indigenous Australians and other cultural minority groups worldwide may be more vulnerable to addiction from opioids and other substances may affect clinicians' approaches to management of both acute and chronic pain in these groups. Certainly, the opioid crisis that is affecting many industrialized countries [15,16] and alcoholrelated addictions are a concern for Indigenous Australians [17], but to assume greater predisposition to opioid addiction is stereotyping, and may be associated with insufficient management of pain. This could explain why some studies report that African Americans (USA) are incompletely and insufficiently managed [18], with this group being prescribed less pain medication for the same condition than Caucasians [19]. The lack of knowledge of Indigenous cultural beliefs surrounding pain [20] and lack of research explicitly seeking to examine the impact of Indigenous-specific factors on pain, is adding to the gap.

The most pragmatic solution for this problem would be applying a person centred care (PCC) approach for collecting information regarding Indigenous pain experience, but that alone is not enough. PCC is endorsed by the Department of Health, Australian Government [8], WHO [21] and Australian Commission on Safety and Quality in Healthcare [22], for effective delivery of health. Integrating the voices and views of Indigenous communities into care planning can also 
be an effective strategy for closing the gap in Indigenous health outcomes. The PCC approach is based on four pillars: patient-as person; biopsychosocial perspective; sharing power and responsibility, and therapeutic alliance [23]. This approach will allow involvement of the patient and general Indigenous community; health care providers and stakeholders who are involved in the provision of or are affected by Indigenous healthcare. Additionally, PCC acts as an ideal vehicle for collection of rich data, which will assist the development, designing and implementation of culturally-relevant scales and strategies [23]. Nevertheless, specific knowledge about the experience and report of pain among Indigenous Australians is necessary in order to provide relevant information to clinicians, patients, and indigenous groups themselves.

In light of these findings, it is imperative that widely used pain assessment scales be studied, and new norms created, or instruments adapted and modified, to more accurately capture Indigenous cultural values and how they frame the experience of pain. Theoretically, conceptualising pain and its associated co-morbidities among the Indigenous Australian population will increase awareness and provide much-needed information about an important health condition. Developing pain assessment instruments that are valid and reliable in the Indigenous health context may produce findings that can facilitate developing a framework for tailored pain measurement and management which can also be applied to broader spectrum of health conditions observed in Indigenous Australians and, indeed, to Indigenous populations at an international level.

Disclosure of interest

The authors have no conflict of interests to report.

Funding

This research did not receive any specific grant from funding agencies in the public, commercial, or not-for-profit sectors.

\section{References}


1. Merskey H. Classification of chronic pain. Description of chronic pain syndromes and definitions of pain terms. 1994:1-213.

2. Economics A. The High Price of Pain: The Economic Impact of Persistent Pain in Australia. Report by Access Economics Pty Limited for MBF Foundation in Collaboration with University of Sydney Pain Management Research Institute.

3. Conway J, Higgins I. Literature review: models of care for pain management. Sax Institute: Sydney. 2011 Oct.

4. Coggon D. Occupational medicine at a turning point. 2005

5. Hole RD, Evans M, Berg LD, Bottorff JL, Dingwall C, Alexis C, et al. Visibility and voice: Aboriginal people experience culturally safe and unsafe health care. Qualitative health research. 2015 Dec;25(12):1662-74.

6. Kowal EE, Paradies YC. Enduring dilemmas of Indigenous health. Med J Aust. 2010 May 17;192(10):599-600.

7. International Pain Summit of the International Association for the Study of Pain. Declaration of Montreal: declaration that access to pain management is a fundamental human right. Journal of pain \& palliative care pharmacotherapy. 2011 Mar 15;25(1):2931.

8. Department of the Prime Minister and Cabinet. National Strategic Framework for Aboriginal and Torres Strait Islander Peoples' Mental Health and Social and Emotional Wellbeing 2017-2023. 2017

9. Lin IB, Ryder K, Coffin J, Green C, Dalgety E, Scott B, et al. Addressing disparities in low back pain care by developing culturally appropriate information for aboriginal australians:"My Back on Track, My Future”. Pain Medicine. 2017 Jan 13;18(11):207080.

10. National Health and Medical Research Council. Acute pain management: scientific evidence. Canberra. 1999

11. Fenwick C, Stevens J. Post operative pain experiences of Central Australian Aboriginal women. What do we understand?. Australian Journal of Rural Health. 2004 Feb $1 ; 12(1): 22-7$.

12. Fenwick C. Assessing pain across the cultural gap: Central Australian Indigenous peoples' pain assessment. Contemporary nurse. 2006 Sep 1;22(2):218-27.

13. Vindigni D, Griffen D, Perkins J, Da Costa C, Parkinson L. Prevalence of musculoskeletal conditions, associated pain and disability and the barriers to managing these conditions in a rural, Australian Aboriginal community. Rural and Remote Health. 2004 Aug 27;4:230.

14. Alvarado AJ. Cultural Diversity: Pain Beliefs and Treatment among MexicanAmericans, African-Americans, Chinese-Americans and Japanese-Americans. 2008

15. Kolodny A, Courtwright DT, Hwang CS, Kreiner P, Eadie JL, Clark TW, Alexander GC. The prescription opioid and heroin crisis: a public health approach to an epidemic of addiction. Annual review of public health. 2015 Mar 18;36:559-74.

16. Lasser KE. Prescription Opioid Use Among US Adults: Our Brave New World. Annals of internal medicine. 2017 Sep 5;167(5):351-2.

17. Calabria B, Doran CM, Vos T, Shakeshaft AP, Hall W. Epidemiology of alcoholrelated burden of disease among Indigenous Australians. Australian and New Zealand journal of public health. $2010 \mathrm{Jul} 1 ; 34$ (s1).

18. Hoffman KM, Trawalter S, Axt JR, Oliver MN. Racial bias in pain assessment and treatment recommendations, and false beliefs about biological differences between blacks and whites. Proceedings of the National Academy of Sciences. 2016 Apr 19;113(16):4296-301. 
19. Dickason RM, Chauhan V, Mor A, Ibler E, Kuehnle S, Mahoney D, Armbrecht E, Dalawari P. Racial differences in opiate administration for pain relief at an academic emergency department. Western Journal of Emergency Medicine. 2015 May;16(3):372.

20. Aspin C, Brown N, Jowsey T, Yen L, Leeder S. Strategic approaches to enhanced health service delivery for Aboriginal and Torres Strait Islander people with chronic illness: a qualitative study. BMC health services research. 2012 Dec;12(1):143.

21. World Health Organization. The world health report 2000: health systems: improving performance. World Health Organization; 2000.

22. Australian Commission on Safety and Quality in Health Care. Patient-centred care: Improving quality and safety through partnerships with patients and consumers, ACSQHC, Sydney. 2011

23. Ekman I, Wolf A, Olsson LE, Taft C, Dudas K, Schaufelberger M, et al. Effects of person-centred care in patients with chronic heart failure: the PCC-HF study. European heart journal. 2011 Sep 15;33(9):1112-9. 